\title{
Phrenic nerve injury in infants and children undergoing cardiac surgery
}

Q Mok, R Ross-Russell, D Mulvey, M Green, E A Shinebourne

\begin{abstract}
Fifty infants and 50 children less than 15 years undergoing palliative or corrective cardiac surgery in the Brompton Hospital between March and October 1988 had direct percutaneous stimulation of the phrenic nerve before and after operation. Ten patients, six under 1 year of age and four over, developed unilateral phrenic nerve injury. In those aged less than 1 year recovery after operation was prolonged because their diaphragmatic palsy made it difficult to wean them from the ventilator. Older children had symptoms but their rate of recovery did not seem to be affected by the phrenic nerve injury. Phrenic nerve damage was no more frequent after a lateral thoracotomy than after a median sternotomy. There was no significant association with the type of operation performed, the experience of the surgeon, the use of bypass or topical ice, the duration of bypass, circulatory arrest or aortic cross clamping, or the age of the patient at the time of operation. In patients who had cardiopulmonary bypass the risk of injury was significantly higher in those who had undergone previous operation. The $10 \%$ frequency of phrenic nerve injury determined in this prospective study was higher than that seen in earlier retrospective reports.

Direct percutaneous stimulation of the phrenic nerve can be used at the bedside in infants and children to facilitate early and accurate diagnosis of phrenic nerve palsy, and the results may influence early management.
\end{abstract}

Phrenic nerve injury is a known complication of cardiac surgery ${ }^{12}$ that results in paralysis of the diaphragm and impairs respiratory function. It can prolong the postoperative course. Such injury was found in $0.5 \%$ to $2.2 \%$ of paediatric patients in retrospective studies. ${ }^{3-7}$ In these studies the criteria for diagnosis were difficulty in weaning from a ventilator, a raised hemidiaphragm on chest radiographs, or decreased or paradoxical diaphragmatic movement on fluoroscopy. Percutaneous phrenic nerve stimulation is an established technique for assessing nerve function. ${ }^{8-11}$ The technique was used in two small groups of adult patients to measure the incidence of phrenic nerve injury after cardiac surgery; incidences of $8 \%$ and $11 \%$ were obtained. ${ }^{1213}$
This non-invasive technique was modified for use in infants and children in the Brompton Hospital in a preliminary study ${ }^{14}$ and normal values have also been established (in preparation). We performed a prospective study of 100 infants and children undergoing cardiac surgery to determine the frequency and predisposing factors contributing to phrenic nerve injury.

\section{Patients and methods}

The study was approved by the hospital medical ethics committee and parental consent was obtained. We studied 100 unselected infants and children undergoing palliative or corrective surgery for congenital heart disease in the Brompton Hospital between March and October 1988. Figure 1 shows their age distribution which ranged from 1 day to 14.5 years (median age 15 months). Table 1 summarises the diagnoses at operation, the type of operation performed, and the number of children in each group. To assess phrenic nerve involvement phrenic nerve latency was measured before operation and as soon as possible after operation when they were no longer on muscle relaxants. Because the test could be performed while the patients were still on the ventilator, they were studied within 72 hours of operation. Twenty three children had had a previous operation and two of them had pre-existing phrenic nerve injury with a prolonged phrenic nerve latency though both were symptom free when tested before the present operation. Measurements of normal phrenic nerve latency and diaphragmatic electromyograms during preoperative testing showed that all the remaining patients had normal phrenic nerve function.

\section{METHODS}

Each phrenic nerve was stimulated percutaneously by bipolar electrodes at the pos-

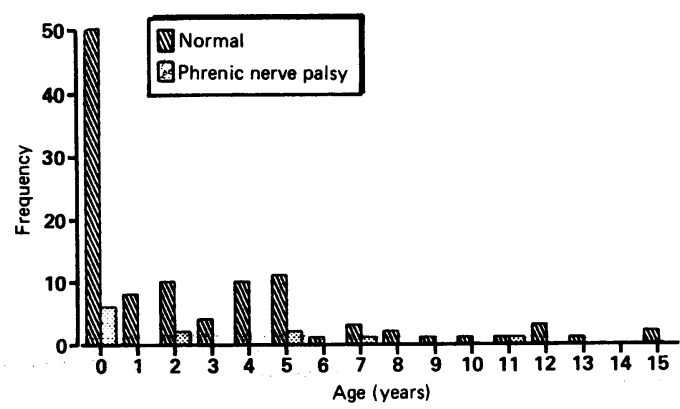

Figure 1 Histogram showing age distribution of 100 patients in the study. 
Table 1 Classification of diagnoses and operation

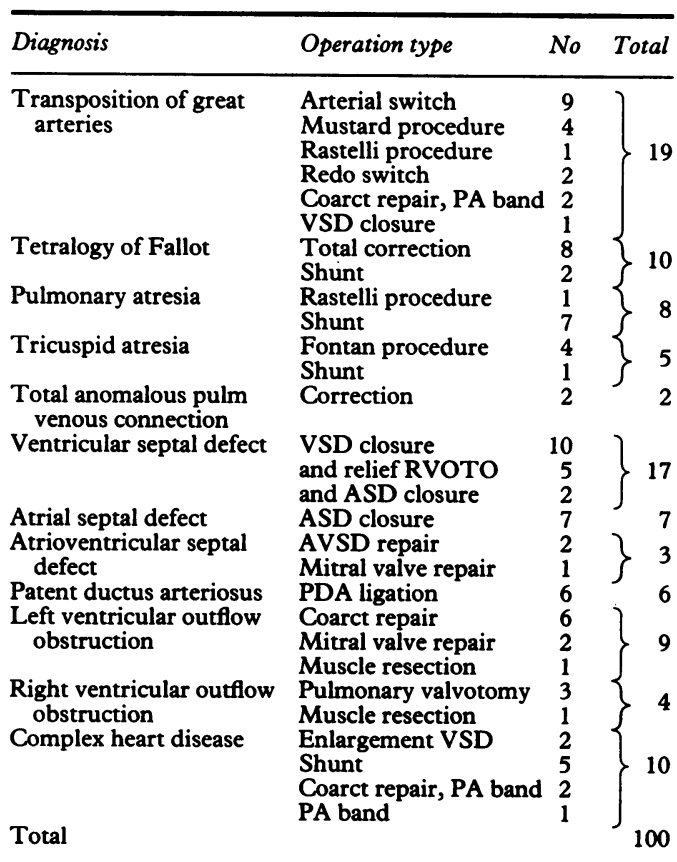

ASD, atrial septal defect; AVSD, atrioventricular septal defect; Coarct, coarctation of the aorta; PA band, pulmonary defect; Coarct, coarctation of the aorta; PA band, pulmonary
artery band; PDA, persistent ductus arteriosus; RVOTO, right artery band; PDA, persistent ductus arteriosus; RVOTO, right
ventricular outflow tract obstruction; VSD, ventricular septal ventricula
defect.

terior border of the sternomastoid at the level of the upper border of the thyroid cartilage..$^{8-11}$ Square wave stimuli with a supramaximal current $(6-45 \mathrm{~mA})$ that lasted $0 \cdot 1-0 \cdot 2 \mathrm{~ms}$ were applied to each nerve at a frequency of $1 \mathrm{~Hz}$. The ipsilateral diaphragmatic compound muscle action potential was detected by surface electrodes placed in the seventh intercostal space at the anterior axillary line. This electromyogram was amplified and displayed on the screen of an oscilloscope and recorded photographically. The earth electrode was placed just below the xiphisternum to avoid disturbing the surgical dressings (figs 2 and 3). Occasional excitation of the brachial plexus was seen because the phrenic nerve lies close to the nerve trunks at the point of stimulation.

The conduction time of the phrenic nerve was measured as the terminal latency between the stimulation artefact and the onset of the diaphragmatic muscle action potential. This gives a reliable assessment of phrenic nerve function. ${ }^{810}$ Phrenic nerve injury was diagnosed if the nerve latency was increased to more than twice the preoperative value or if no detectable diaphragmatic electromyographic or mechanical response was obtained despite supramaximal stimulation on repeated testing (fig 4). We used fluoroscopy to detect paradoxical or reduced movement of the diaphragm in this latter group of patients to confirm the diagnosis of diaphragm paralysis.

We tested the association of phrenic nerve injury with dichotomous factors by the $\chi^{2}$ test with Yates's correction. The Mann-Whitney test was used for other factors.

\section{Results}

Ten patients $(10 \%)$ had abnormal unilateral phrenic nerve latencies after operation. In seven of these patients the phrenic nerve latency was at least twice the preoperative value, while in the remaining three no activity was detected on the diaphragmatic electromyogram. Figure 5 shows the relation between preoperative and postoperative phrenic nerve latencies. Phrenic nerve injury occurred on the right side in four patients and on the left in six patients. In six of the 10 patients cardiopulmonary bypass had been performed via median sternotomies. In four the operation was performed via right or left lateral thoracotomies without bypass. After a lateral thoracotomy phrenic nerve palsy occurred on the same side as the incision. All the ten patients had basal atelectasis or a raised

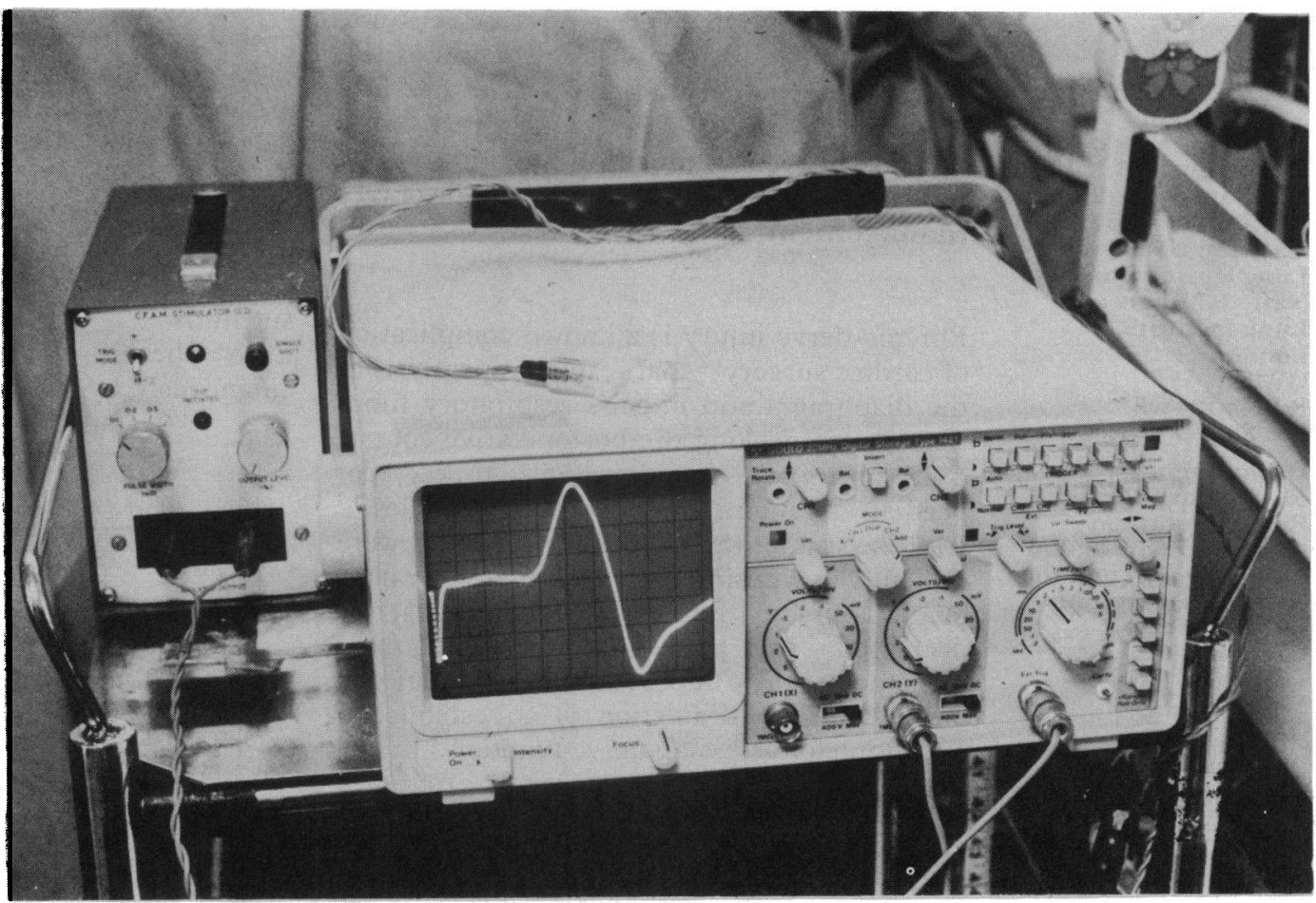

Figure 2 Equipment used to test phrenic nerve: nerve stimulator (left), bipolar electrode modified for use in paediatric patients, and oscilloscope for recording the electromyogram. 
Figure 3 Postoperative test on a ventilated patient showing location of the surface electrodes and position for percutaneous stimulation of phrenic nerve.

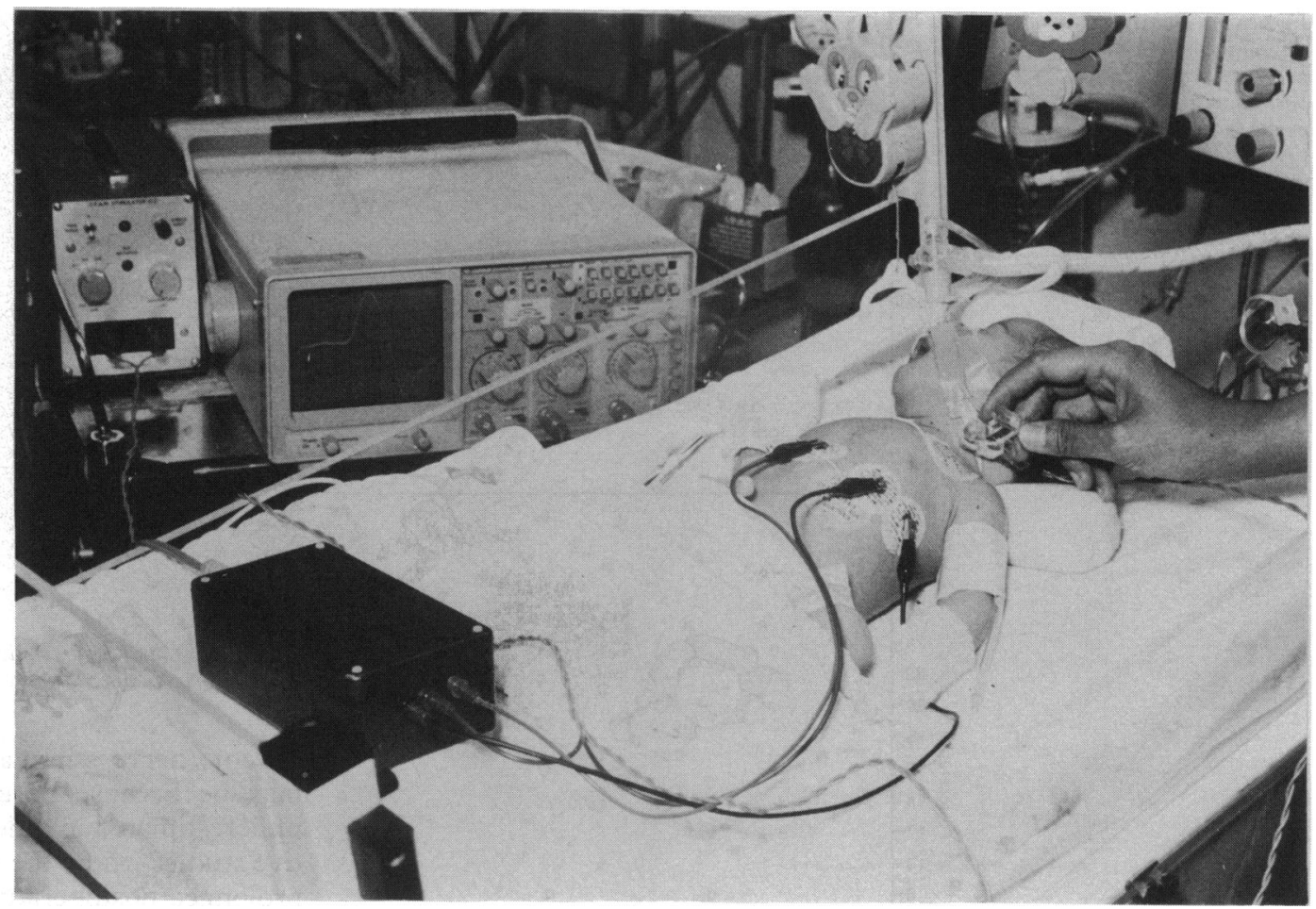

hemidiaphragm on chest $x$ ray (fig 6), though this was often not evident while the patient was on positive pressure ventilation.

Table 2 summarises data on the affected patients and their outcomes. All the children who required a prolonged period of ventilation were less than 1 year old, except for patient 8 who was failing to thrive and weighed $6.8 \mathrm{~kg}$ at the age of 2 , and patient 6 who was ventilated for other reasons and in whom there was evidence of recovery of phrenic nerve function. Four of the neonates subsequently required plication of the affected diaphragm to facilitate extubation, after many attempts to wean them from ventilatory support. Because repeated electrophysiological testing could not be used to predict temporary or permanent damage (as

nerve recovery is slow), plication was performed on clinical grounds. Patients 3 and 8 did not have plication but they were nursed in negative pressure tanks because various other complications precluded further operation. Four of the ten patients eventually died, three as a direct result of respiratory failure caused by diaphragmatic impairment while the remaining patient died from other surgical complications.

We assessed many factors in our attempt to determine associated causes of phrenic nerve injury. These included the underlying diagnosis and type of operation (bypass or nonbypass), the duration of bypass, aortic cross clamping or circulatory arrest, the temperature to which the patient was cooled, the use of topical ice, the experience of the surgeon (con-

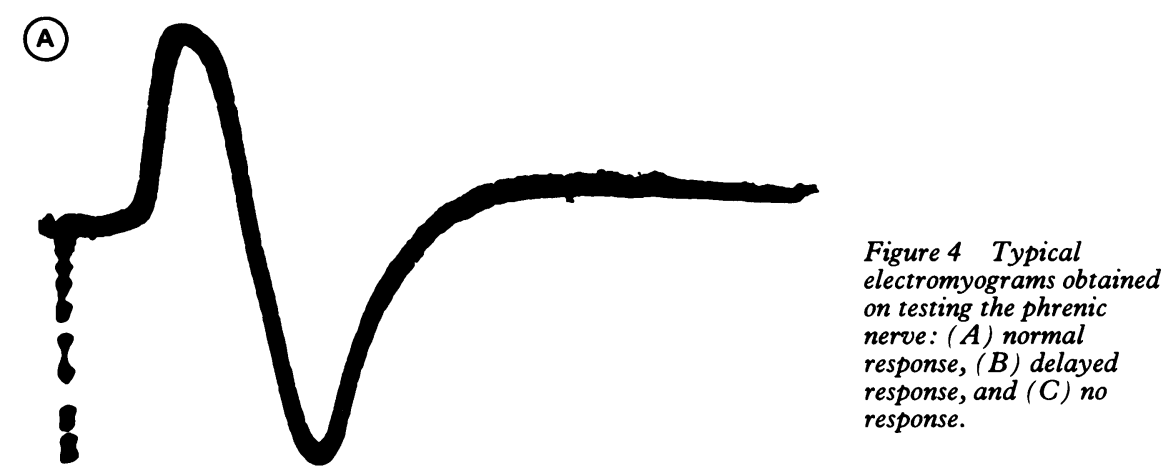

(B)

(C)
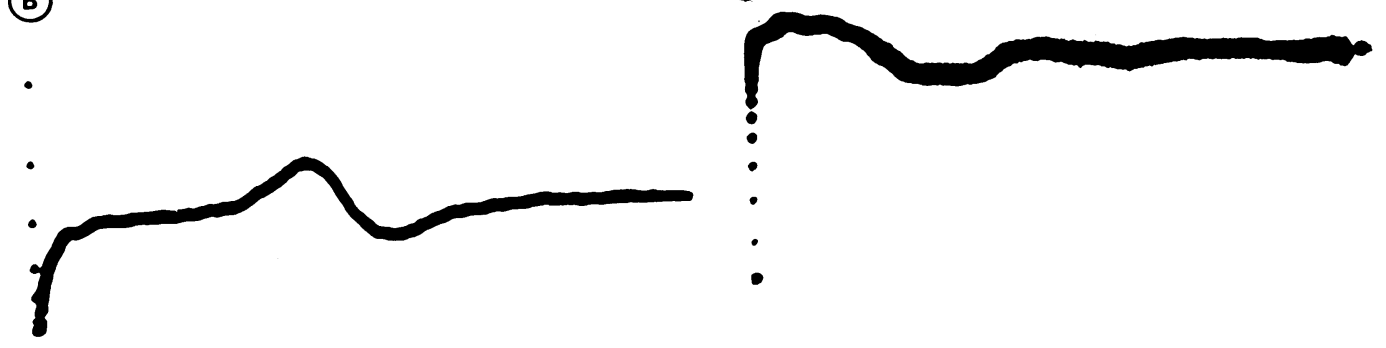
Figure 5 Scattergram of the relation between preoperative and postoperative phrenic nerve latency ( $A)$ left, (B) right). Phrenic nerve injury was defined as postoperative latency of more than twice the preoperative value. Absen responses were assigned a maximum latency of $25 \mathrm{~ms}$.
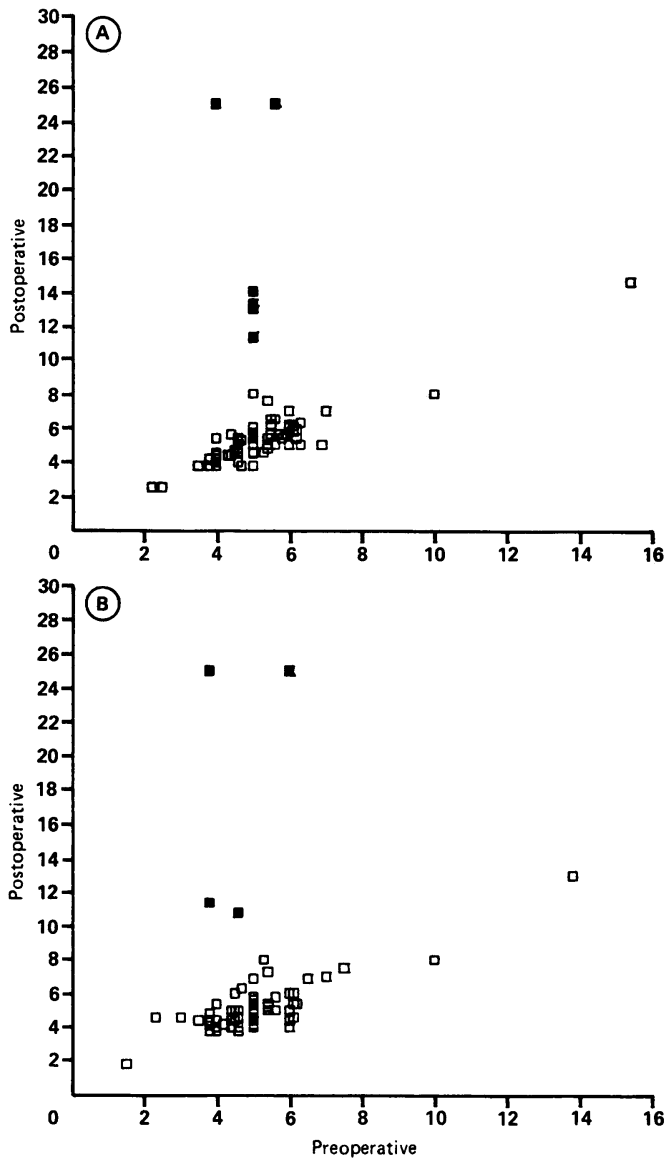

sultant or non-consultant), the presence of previous operations, the incision site, and the age at operation. There was a significant association with previous surgery $(p<0.05)$ in only the 68 bypass cases; however, the phrenic nerve injury after the subsequent operation was not always on the same side as the previous thoracotomy. No other significant associated factor was found though there might have been a marginal risk associated with the experience of the surgeon; consultant surgeons had a smaller risk $(p=0 \cdot 1)$ than with senior registrars or registrars.

\section{Discussion}

We found that the incidence of phrenic nerve injury in paediatric cardiac surgery was higher than was previously reported in retrospective studies $^{3-7}$ but similar to small studies based on

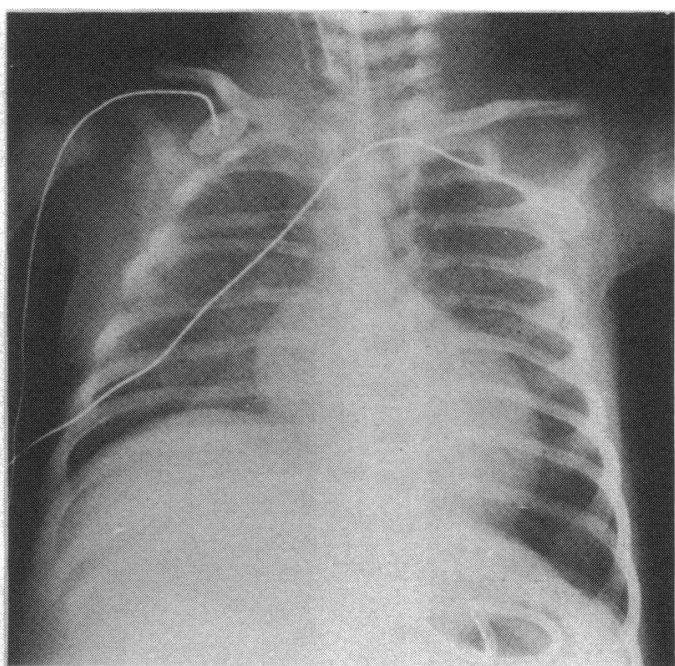

Figure 6 Chest $x$ ray showing raised hemidiaphragm seen in phrenic nerve injury.

phrenic nerve stimulation in adults. ${ }^{12}$ This may be because phrenic nerve damage was underestimated in older children in retrospective studies where the selection was based on a prolonged postoperative course or difficulty in weaning from the ventilator. We found that though phrenic nerve paralysis causes severe respiratory embarrassment in neonates it seems to cause fewer clinical or physiological abnormalities in children who are more than 1 year old, unless there is associated weakness of other respiratory muscles. Respiratory muscle physiology in the older child seems to be similar to that in adults, who cope with unilateral or bilateral diaphragm paralysis with only a few symptoms. ${ }^{1516}$ Retrospective studies also based their diagnoses on the presence of a raised hemidiaphragm on the chest $x$ ray or paradoxical movement of the diaphragm on ultrasound scanning or fluoroscopy. These methods of diagnosis may be unreliable while the patient is on positive pressure ventilation or where there is bilateral phrenic nerve palsy and the true incidence of the condition may be underestimated. ${ }^{61718}$

Infants with phrenic nerve injury have an increased morbidity and mortality from the resulting diaphragmatic palsy. ${ }^{356}$ They require a significantly longer period of ventilation because of episodes of acute respiratory distress. This is because of major differences in the respiratory physiology in infants. ${ }^{1920}$ Contrac-

Table 2 Data on patients with phrenic nerve injury

\begin{tabular}{|c|c|c|c|c|c|c|}
\hline $\begin{array}{l}\text { Case } \\
\text { No }\end{array}$ & Diagnosis & Operation & Age & Side & Ventilation & Plication \\
\hline 1 & TGA, VSD, Coarct & PA band, Coarct repair & 2 days & $\mathrm{L}$ & IPPV 24 days & + \\
\hline 2 & PA, VSD & Left shunt & 1 day & $\overrightarrow{\mathrm{L}}$ & IPPV 14 days & + \\
\hline 3 & TGA & Mustard & $3.5 \mathrm{mnth}$ & $\mathrm{L}$ & IPPV 36 days, CNEP 30 days & - \\
\hline 4 & TGA, PS, Switch & Redo RVOT & $2 \mathrm{yr}$ & $\mathrm{L}$ & IPPV 1 day & - \\
\hline 5 & MS & MV repair & $11.5 \mathrm{yr}$ & $\mathbf{R}$ & IPPV 12 hours & - \\
\hline 6 & TA, PA band & Fontan & $5.5 \mathrm{yr}$ & $\mathbf{R}$ & IPPV 19 days & - \\
\hline 7 & TGA & Switch & 3 days & $\mathrm{L}$ & IPPV 14 days & - \\
\hline 8 & TGA, vSD, Coarct rep, & Switch & $2 \cdot 3 \mathrm{yr}$ & $\mathrm{L}$ & IPPV 27 days, CNEP 60 days & - \\
\hline 9 & $\begin{array}{l}\text { PA band } \\
\text { TGA, PS }\end{array}$ & Right shunt & 1 day & $\mathbf{R}$ & IPPV 28 days & + \\
\hline 10 & TGA, PS & Right shunt & 2 days & $\mathbf{R}$ & IPPV 51 days & + \\
\hline
\end{tabular}

Coarct, coarctation of the aorta; CNEP, continuous negative extrathoracic pressure ventilation; IPPV, intermittent positive pressure ventilation; MS, mitral stenosis; MV, mitral valve; PA, pulmonary atresia; PA band, pulmonary artery band; PS, pulmonary stenosis; RVOTO, right ventricular outflow tract obstruction; TGA, transposition of the great arteries; VSD, ventricular septal defect. 
tion of the diaphragm is less efficient in infants because they have a circular thorax, horizontal orientation of the ribs, and greater compliance of the rib cage. In normal breathing in adults the diaphragm stabilises the thorax during inspiration. $^{2122}$ This effect is especially important in infants because they have weaker intercostal muscles. In supine adults the abdominal contents press on the diaphragm and reduce the functional residual capacity by $15 \% .{ }^{23}$ This expected reduction in functional residual capacity in the supine infants is aggravated in phrenic nerve injury where the loss of the hydraulic piston effect and the raising of the flaccid diaphragm reduce the parenchymal lung volume even more. This increases atelectasis and mediastinal shift so much that both factors interfere with respiration in both the affected and normal lung. ${ }^{24}$ Younger infants are also more susceptible to fatigue of the diaphragm because of the smaller proportion of type I (slow twitch, high oxidative) muscle fibres. ${ }^{25}$

Previous studies have implicated "frostbite injury" from the topical slush used for myocardial preservation in bypass surgery as the cause of phrenic nerve injury ${ }^{17}$ and this hypothesis was confirmed by experiments in dogs. ${ }^{26}$ Several workers suggested that the use of various insulation pads reduced the incidence. ${ }^{28-30} \mathrm{We}$, however, found that phrenic nerve damage was as common in non-bypass surgery in which neither cold cardioplegic solutions nor topical ice was used. There was also no association with the cooling temperature or duration of bypass, suggesting that other factors, for example direct or indirect surgical trauma, may be equally important.

Secondary procedures after previous thoracotomies can increase the incidence of phrenic nerve paralysis. ${ }^{56}$ The presence of fibrous adhesions and scarring from previous operation would obscure the anatomy of the pericardium and phrenic nerve and make them more liable to injury. We also found an association between phrenic nerve injury and previous operation but only when bypass cases were considered separately. The reason for this is unclear but it could be that a combination of more demanding bypass surgery and scarring from previous operations contributed to the higher risk. A closer examination of the data in references 5 and 6 bears this out because the association of phrenic nerve injury with previous thoracotomies was found only among patients who had open heart surgical procedures.

There was no obvious association between phrenic nerve injury and the age at operation, the type of surgery, or the incision site. The duration of bypass, aortic cross clamping or circulatory arrest, and the temperature to which the patient was cooled were not found to be significant factors. There may have been too few patients affected in this study to show an association.

Phrenic nerve paralysis can result in many complications including episodes of aspiration, respiratory infections, cardiac arrhythmias, or cardiorespiratory arrests and death. ${ }^{1}$ Various workers have suggested different methods of management to overcome this problem, recommending repair of the transected nerve,${ }^{31}$ long term ventilation with or without tracheostomy, ${ }^{32}$ and early ${ }^{3}$ or late ${ }^{4-6}$ plication of the diaphragm. We found that plication of the diaphragm reduced complications from prolonged ventilation because it allowed earlier extubation. The decision to plicate could be taken with greater assurance and less delay because phrenic nerve injury was accurately assessed by this technique. It did not, however, seem to improve survival rates in the patients with phrenic nerve injury and persistent diaphragmatic palsy.

Phrenic nerve conduction studies can be easily performed at the bedside with the equipment and technique described above. Early and accurate detection of phrenic nerve injury is possible while the patient is ventilated, before clinical or radiological evidence of diaphragmatic dysfunction. Phrenic nerve injury is a common and important complication of cardiac surgery in infants and children that increases morbidity and mortality. Early detection of injury identifies the infants who may require early diaphragmatic plication, thus preventing an unnecessary and prolonged course of ventilation and the associated complications.

We thank MrV Aber for help with statistical analysis of the data

1 Sethi G, Reed WA. Diaphragmatic malfunction in neonates and infants: diagnosis and treatment. J Thorac Cardiovasc Surg 1971;62:138-43.

2 Mearns AJ. Iatrogenic injury to the phrenic nerve in infants and young children. Br J Surg 1977;64:558-60.

3 Shoemaker R, Palmer G, Brown JW, King H. Aggressive treatment of acquired phrenic nerve paralysis in infants treatment of acquired phrenic nerve paralysis in infant

4 Lynn AM, Jenkins JG, Edmonds JF, Burns JE. Diaphrag matic paralysis after pediatric cardiac surgery: a retromatic paralysis after pediatric cardiac surgery: a retro-
spective analysis of 34 cases. Crit Care Med 1983; spective

5 Watanabe T, Trusler GA, Williams WG, Edmonds JF, Coles JG, Hosokawa Y. Phrenic nerve paralysis after pediatric cardiac surgery: retrospective study of 125 cases. $J$ Thorac Cardiovasc Surg 1987;94:383-8.

6 Mickell JJ, Oh KS, Siewers RD, Galvis AG, Fricker FJ, Mathews RA. Clinical implications of postoperative unilateral phrenic nerve paralysis. $J$ Thorac Cardiovasc Surg 1978;76:297-304.

7 Zhao HX, D'Agostino RS, Pitlick PT, Shumway NE, Miller DC. Phrenic nerve injury complicating closed cardiovascular surgical procedures for congenital heart disease. Ann Thorac Surg 1985;39:445-9.

8 Newsom Davis J. Phrenic nerve conduction in man. J Neurol Neurosurg Psychiatry 1967;30:420-6.

9 McKenzie DK, Gandevia SC. Phrenic nerve conduction times and twitch pressures of the human diaphragm times and twitch pressures of the
$J$ Appl Physiol 1985;58:1496-504.

10 Markand ON, Kincaid JC, Pourmand RA, et al. Electrophysiologic evaluation of diaphragm by transcutaneous phrenic nerve stimulation. Neurology 1984;34:604-14.

11 Mier A, Brophy C, Moxham J, Green M. Phrenic nerve stimulation in normal subjects and in patients with diaphragmatic weakness. Thorax 1987;42:885-8.

12 Estenne M, Yernault JC, De Smet JM, De Troyer A. Phrenic and diaphragm function after coronary artery bypass grafting. Thorax 1985;40:293-9.

13 Markand ON, Moorthy SS, Mahomed Y, King RD, Brown JW. Postoperative phrenic nerve palsy in patients with open-heart surgery. Ann Thorac Surg 1985;39:68-73.

14 Ross-Russell RI, Mulvey D, Laroche C, Shinebourne EA, Green M. Bedside assessment of phrenic nerve function in infants and children. J Thorac Cardiovasc Surg 1991; 101:143-7.

15 Laroche CM, Carroll N, Moxham J, Green M. The clinical significance of severe isolated diaphragm weakness. Am
Rev Respir Dis 1988;138:862-5. 6 Laroche CM, Mier AK, Moxham J, Green M. Diaphragm strength in patients with recent hemidiaphragm paralysis. Thorax 1988;43:170-4.

17 Kohorst WR, Schonfeld SA, Altman M. Bilateral diaphragmatic paralysis following topical cardiac hypothermia. Chest 1984;85:65-8.

18 Chandler KW, Rozas CJ, Kory RC, Goldman AL. Bilateral diaphragmatic paralysis complicating local cardiac hypothermia during open heart surgery. $A m \mathrm{~J}$ Med 1984;77:243-9. 
19 Muller NL, Bryan AC. Chest wall mechanics and respiratory muscles in infants. Pediatr Clin North Am 1979;26:503-16.

20 Bryan AC, Wohl MEB. Respiratory mechanics in children In: Fishman AP, Macklem PT, Mead J, eds. Handbook of physiology section 3: The respiratory system. Bethesda, physiology section 3: The respiratory system. Bethesda, Part 1:179-91.

21 Green M, Moxham J. The respiratory muscles. Clin Sci 1985;68:1-10.

22 Green M, Moxham J. Respiratory muscles. In: Flenley DC Petty TL, eds. Recent advances in respiratory medicine. Edinburgh: Churchill Livingstone, 1983:1-20.

23 Agostoni E, Mognoni P, Torri G. Relation between changes of rib cage circumference and lung volume. J Appl Physio 1965;20:1179-86.

24 Clague HW, Hall DR. Effect of posture on lung volume: airway closure and gas exchange in hemidiaphragmatic paralysis. Thorax 1979;34:523-6.

25 Keens TG, Bryan AC, Levison H, Ianuzzo CD. Developmental pattern of muscle fibre types in human ventilatory muscles. J Appl Physiol 1978;44:909-13.

26 Marco JD, Hahn JW, Barner HB. Topical cardiac hypo- thermia and phrenic nerve injury. Ann Thorac Surg 1977;23:235-8.

27 Dureuil B, Viires N, Pariente R, Desmonts JM, Aubier M. Effects of phrenic nerve cooling on diaphragmatic function. J Appl Physiol 1987;63:1763-9.

28 Rousou JA, Parker T, Engelman RM, Breyer RH. Phrenic nerve paresis associated with the use of iced slush and the cooling jacket for topical hypothermia. J Thorac Carcooling jacket for topical hypothermia. J Thorac CarWhovasc Surg 1985;89:921-5.

Wheeler WE, Rubis LJ, Jones CW, Harrah JD. Etiology and
prevention of topical cardiac hypothermia-induced phrenic nerve injury and left lower lobe atelectasis during cardiac surgery. Chest 1985;88:680-3.

30 Esposito RA, Spencer FC. The effect of pericardial insulation on hypothermic phrenic nerve injury during open heart surgery. Ann Thorac Surg 1987;43:303-8.

31 Merav AD, Attai LA, Condit DD. Successful repair of a transected phrenic nerve with restoration of diaphragmatic function. Chest 1983;84:642-4.

32 Stewart S, Alexson C, Manning J. Bilateral phrenic nerve paralysis after the Mustard procedure: experience with
four cases and recommendations for management. $J$ Thorac Cardiovasc Surg 1986;92:138-41. 